\title{
SUDDEN MENTAL DETERIORATION WITH CONVULSIONS IN INFANCY
}

\author{
BY \\ R. S. ILLINGWORTH \\ From the Children's Hospital, Sheffield
}

(RECEIVED FOR PUBLICATION JULY 18, 1955)

A wide variety of diseases in infancy is associated with convulsions and mental deterioration. In many there are spasticity, ataxia or other abnormal neurological signs. In other children presenting with convulsions followed by mental deterioration there are no abnormal neurological signs apart from those of the mental changes.

Most writers ascribe the mental changes to the convulsions, though a few have suggested that both fits and mental deterioration may be due to underlying disease of the brain. From experience at the Children's Hospital, Sheffield, I believe that there is a clear-cut group of cases in which a child develops normally up to a certain age, and then practically simultaneously develops fits and mental deterioration. I have not found a reference in the literature to this type of case. In a second group development proceeds normally up to a certain age, and then fits develop; at some subsequent period, often many months or years later, mental deterioration becomes manifest. This paper describes cases belonging to the former group.

\section{The Present Study}

Between 1947 and 1954 I have seen 12 children who developed normally for a period and then almost simultaneously developed epilepsy and underwent mental deterioration. None of the children were born prematurely. Only one of the 12 children (No. 10) had an abnormal delivery, and he was the only one who was ill at birth or in the immediate post-natal period. In none of the other children was there any history of asphyxia at birth, vomiting, cyanotic attacks, respiratory or feeding difficulties, convulsions, twitching or cerebral irritability. In only one child (No. 9) was there a family history of epilepsy; in this case a sibling, who was doing very well at an ordinary school, had petit mal attacks. A cousin of one boy (No. 7) was mentally defective, but there was no other history of mental defectiveness in the family.
All 12 children developed normally for the first few weeks of life, responding at the usual age to social overture, vocalizing, taking interest in their surroundings and using their hands in the normal way. All were well, thriving children, with a good weight and no evidence of rickets.

The age of onset of the illness in these children was 4 to 8 months. In five cases the onset was at 5 months of age. There was no precipitating factor for the illness in any case. No child had any injury, fever or diarrhoea before the onset of the convulsions or mental change. One child (No. 6) had a trivial cold, without fever, at the time of the onset of the fits.

In eight children fits were the first abnormality noted. In the remaining four there were probable premonitory symptoms. One child (No. 1) cried excessively for the two weeks before the first convulsion, having previously been well behaved. Another (No. 3) was said to 'look vacant' (all through the day) for a week before the convulsions occurred. Another (No. 4) became irritable six weeks before fits were noted, taking much less notice of his surroundings and crying continuously, even in his mother's arms. The other child (No. 10) stopped smiling and became dull and staring two weeks before the first fit. In six children the first fits noticed were minor motor convulsions, using the classification adopted by Livingston (1954). In a further five children the convulsions were of the major motor type, and in one they were 'salaam spasms' or akinetic seizures.

The striking feature in the history of all cases was the sudden change in the social responsiveness and in the interest in their surroundings. All eight children whose first symptom was a fit, from the time of the first convulsion, or at least within a day or two of it, stopped smiling and laughing and stopped taking an interest in their surroundings, becoming dull and apathetic. It was only after several months that these children began to smile again, and to show interest in the environment, and 
then the smiling was only occasional, at least for many months, and the interest shown in the surroundings was only fleeting.

The children were first seen by me at varying intervals after the onset. In eight children who were seen within eight weeks of the onset, there was a remarkable dissociation or lack of parallelism between the relatively normal or quite normal motor and manipulative development and the absence of smiling and laughing, and the total lack of interest in the surroundings, so marked in three cases that it was thought (wrongly) that the children were blind. Though this was only to be expected, in view of the previous normal development, the finding is most unusual, and the unwary, assessing a child merely by the development of sitting and locomotion, would fail to notice the highly significant intellectual' changes. In two of these children, seen very shortly after the onset, I gave the parents a bad prognosis on the grounds of these 'intellectual' changes, in spite of normal motor development, and the prognosis proved in later years to be correct, for they are now both aments. In none of the children seen early after the onset was there any significant retardation in motor development and in the use of the hands.

In all cases the rest of the clinical examination was negative, there being no other abnormal neurological signs or abnormal signs elsewhere. The fundi in all cases were normal. The head size, the anterior fontanelle and the cranial sutures were normal.

All investigations with the exception of air encephalograms and electroencephalograms were negative. The Wassermann reaction was negative in all 12 children. The urine of none of the 12 children contained phenylpyruvic acid. A radiograph of the skull was taken in 11 of the children and was normal in all. Tests for toxoplasmosis were carried out in five and were negative. The cerebrospinal fluid was examined in six children within a month of the onset and in two other children at a somewhat later date, and it was normal. In retrospect it is regrettable that subdural taps were carried out only in four children. All were negative. The serum calcium was estimated in two children. It is also regrettable that air encephalograms were only carried out in two cases (Nos. 6 and 9). Livingston (1954) described a child who had a known cerebral haemorrhage at birth and who developed normally until the age of 5 months, when a fit occurred. An air encephalogram showed a cyst in the right frontal region which was removed: the child subsequently improved, though with a residual low I.Q. (69). In Case 6 the air encephalo- gram at the age of 3 years and 8 months was normal. In Case 9 there was distension of the ventricles, but no definite evidence of cortical atrophy (Figs. 1 and 2).
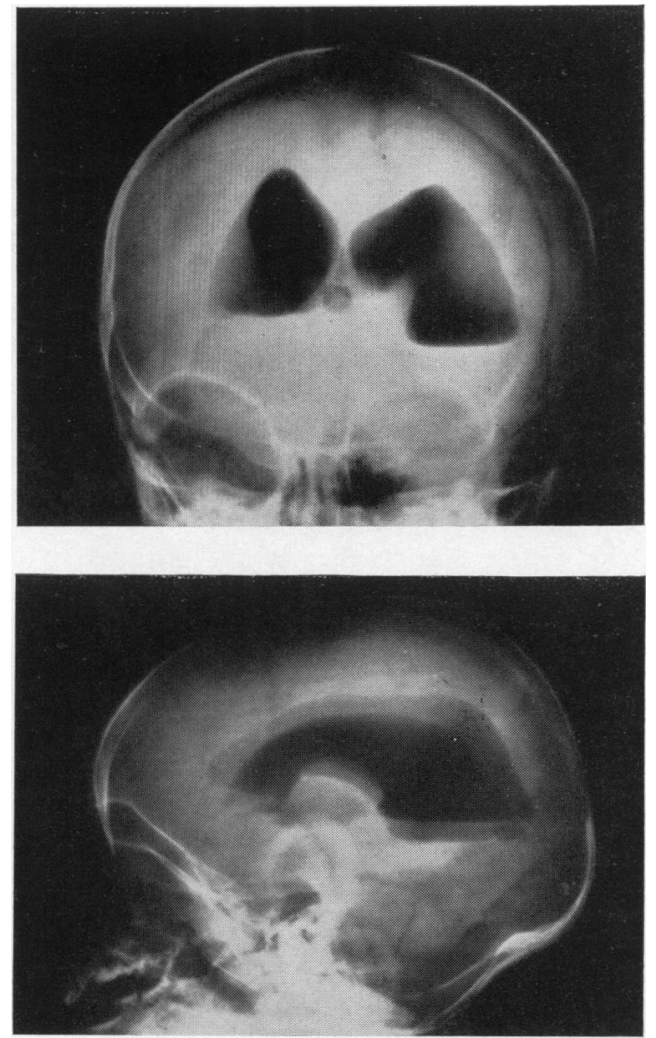

FIGs. 1 and 2.-Air encephalograms of Case 9 at the age of 7 months, showing a considerable degree of symmetrical hydrocephalus. The subarachnoid spaces are not filled with air and cortical atrophy is not demonstrable.

Electroencephalography, using the standard bipolar technique, were carried out at various times in 11 children by Dr. Warboys.

In four cases a tracing was obtained within three months of the onset of the fits and three of them are illustrated here (Figs. 4, 5 and 7). The records of these early cases are all grossly abnormal and contain much generalized paroxysmal slow activity with spikes. The latter vary in location, sometimes appearing focal but actually involving all areas over a period of time. The spikes bear no constant relationship to the slow waves, as they do in petit mal, or to slow spike-and-wave discharges, and these records are quite different from those in petit mal or its variants.

Focal abnormality was found only in Case 1 
SUDDEN MENTAL DETERIORATION WITH CONVULSIONS

531

J.B. 3 yrs. 3 moths. Off drugs

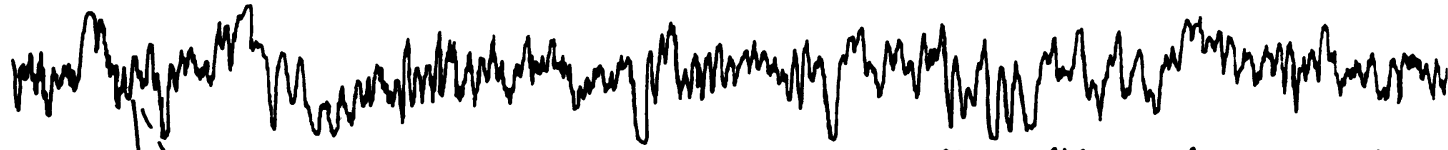

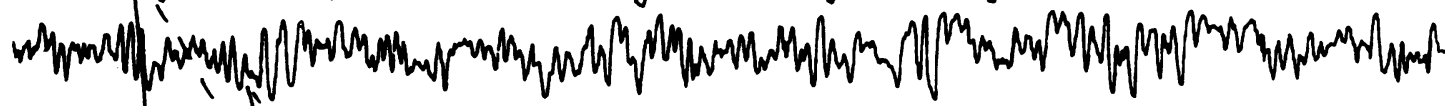

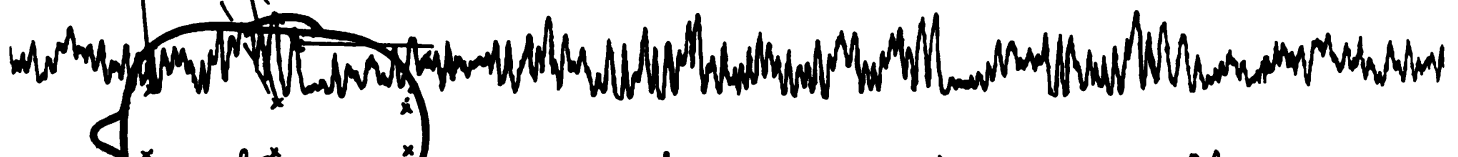

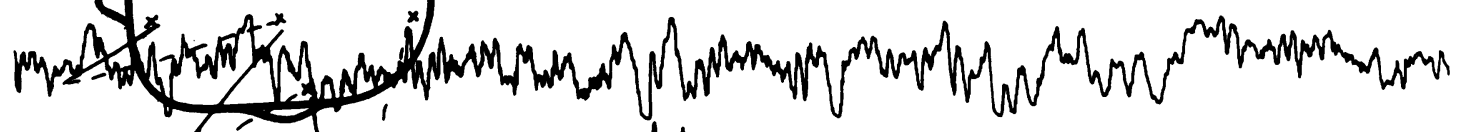

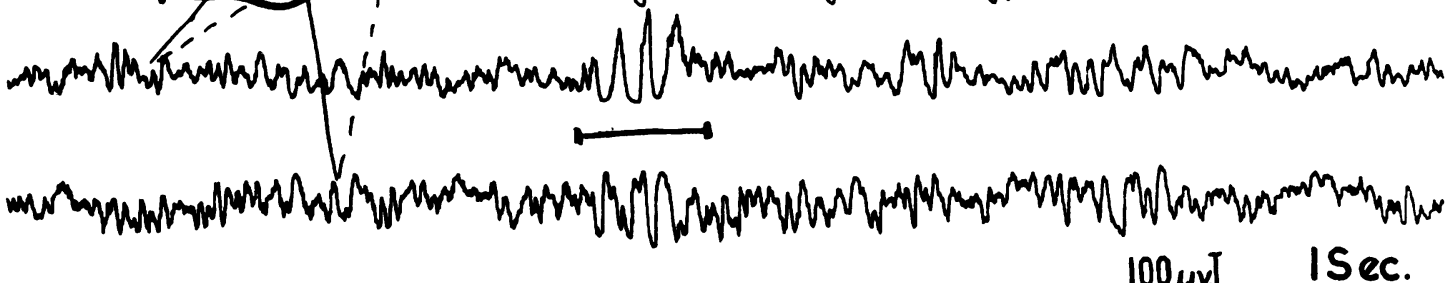
FIG. 3. -Case No. 1, aged 3 years and 3 months, the only case in the series with a focal abnormality -a left temporal epileptogenic focus.

A.B. 7 moths. (light sleep) Off drugs

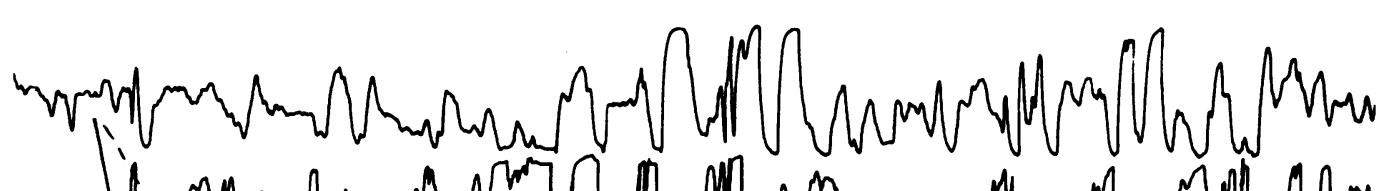

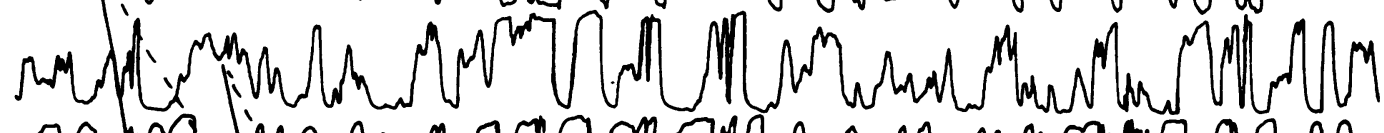

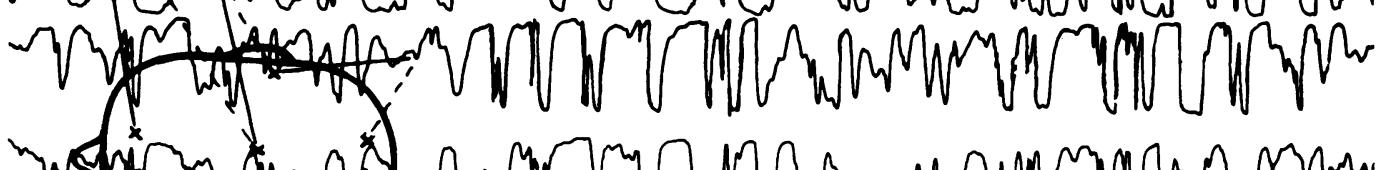
wang

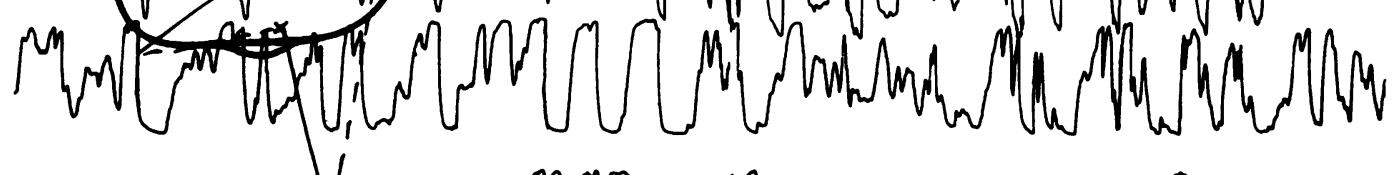

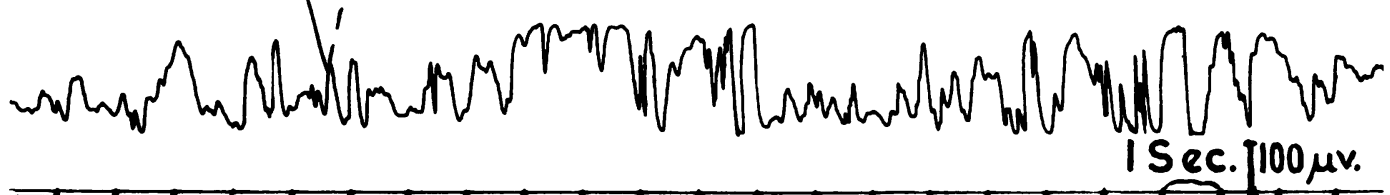
FIG. 4. -Case No. 2, aged 7 months. Light natural sleep, off drugs. Generalized spikes with irregular high-amplitude slow waves. 


\section{L.M. II mths. (Awake) Off drugs}

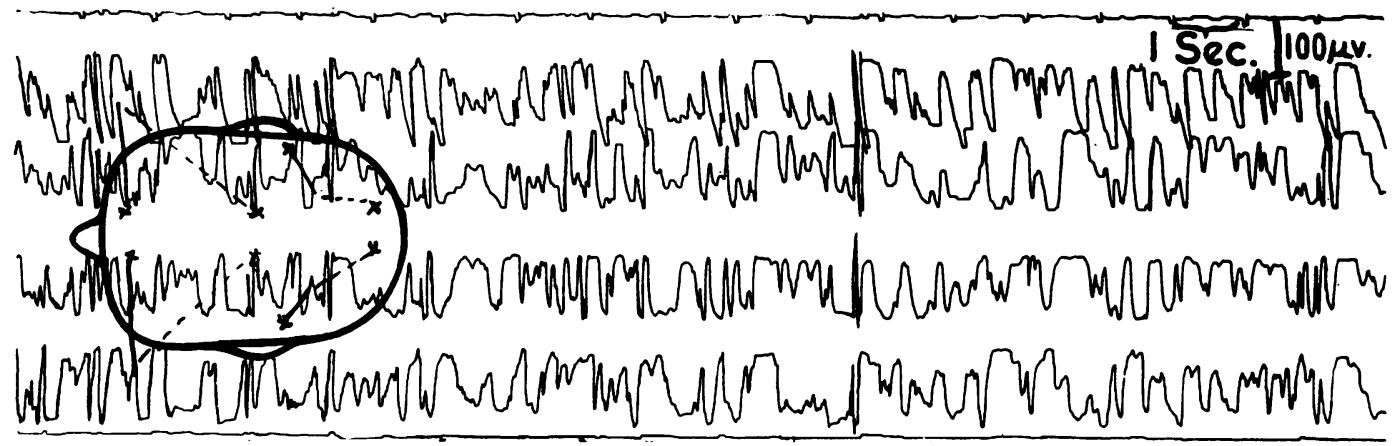

L.M. I yr. 5 mths. (Awake) On anti-convulsants

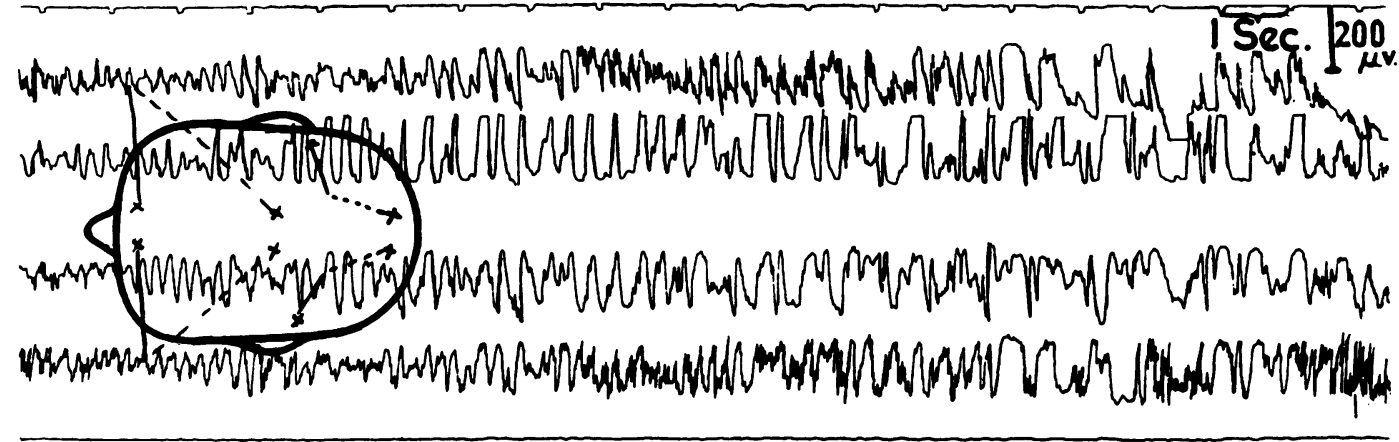

Fig. 5.-Case No. 5, aged 11 months. Awake, off drugs. Generalized spikes and high-amplitude paroxysmal slow waves, with only slight improvement at 17 months on anticonvulsants.

(Fig. 3) and consisted of a paroxysmal slow wave focus in the left temporal lobe. Unfortunately, the first tracing was taken some three years after the onset of fits.

In every case an improvement in the degree of dysrhythmia was noted with age. Little change could be detected within the first two or three years (Fig. 5) in spite of anticonvulsant therapy, but by the age of 4 to 5 years a marked improvement in the tracing was universal (Fig. 6). Seven of the patients are now aged $4 \frac{1}{2}$ years or more and recent tracings were obtained in six of them. The abnormality in these later records consisted of only a mild dysrhythmia with rather a wide range of frequencies for their age and occasional short bursts of generalized slow waves.

The E.E.G. findings indicate a defect of the brain, resulting in a period, between the ages of 5 months and 5 years, of high amplitude explosive electrical activity with fits and amentia.

\section{Clinical Course}

In spite of treatment, consisting of phenobarbitone, phenytoin, troxidone, primidone or metharbital, the fits were for the most part incompletely controlled, though there was a tendency for the fits to cease with age. All the children had several fits a day for several months. It is notable that eight of the children developed akinetic seizures or salaam convulsions, and one had these at the onset, making a total of nine. In all these nine the salaam attacks were very frequent, up to 40 a day being noted by the parents. It is well known that these attacks respond badly to treatment, but in retrospect it is clear that the drugs used were not pushed to the limit of tolerance and that insufficiently determined efforts were made to control them. Nevertheless, from the experience of others it is doubtful whether we could have achieved significantly better results.

As for the general development of these children, 
Case 2 has not been followed up sufficiently long for final assessment. Some of the parents thought that after a few months the children improved, but it was clear on examination that their mental age was not gaining or even keeping up with their chronological age. Case 4, 46 months after the onset, had progressed surprisingly well, and his I.Q. was in the region of 60 . All the others, without exception, were aments, with an I.Q. too low to assess.

Below are brief summaries of the case histories of these children.

\section{Case Histories}

Case 1. This girl began to smile at 6 weeks of age and to laugh aloud at 4 months. She turned her head to sound at 3 months. She was able to take hold of objects at 5 months.

At $5 \frac{1}{2}$ months she began to cry a great deal without apparent reason, but appeared to be normal otherwise until fits began two weeks later. In the fits the limbs seemed to tremble, there was conjugate deviation of the eyes upwards, and the arms stiffened. Each attack lasted for a few seconds, and there were three or four a day from that time onwards. From the time of the first fit, smiling ceased, and the baby stopped taking an interest in her surroundings. She lost her ability to grasp objects.

On examination at 9 months her motor development was that of a 6-month-old child, and she was unable to grasp objects. There was a notable lack of interest in test objects and an absence of smiling and play. Sub-

K.M. 3 yrs. 6 mths. (Awake) On anti-convulsants

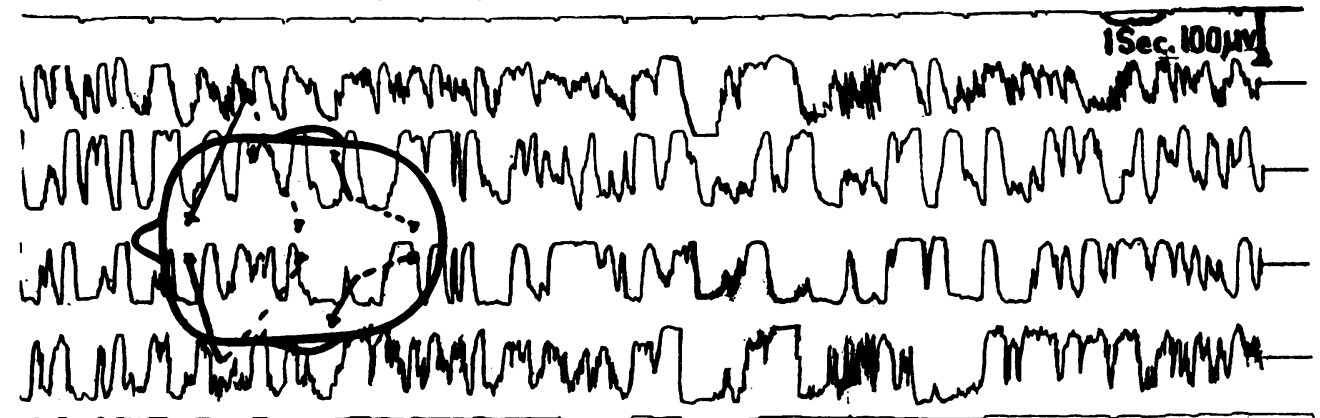

K.M. 5 yrs. 7 mths. On anti-convulsants

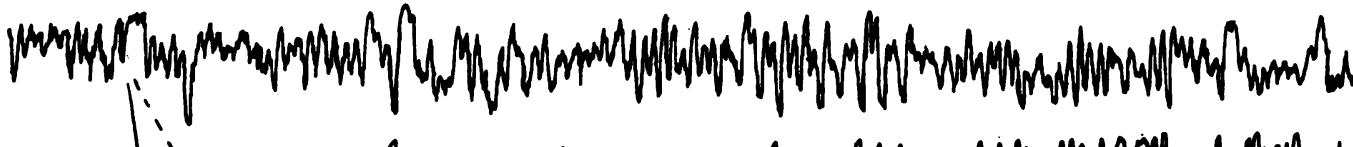

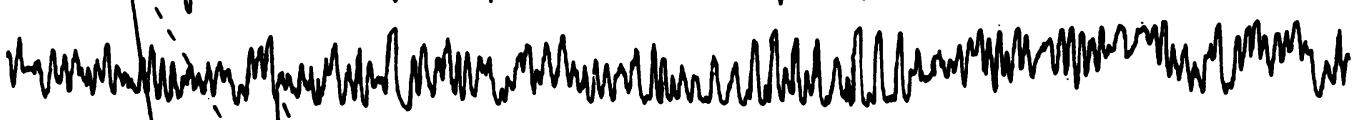

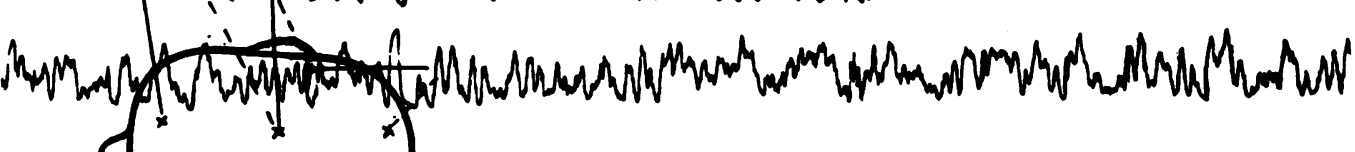

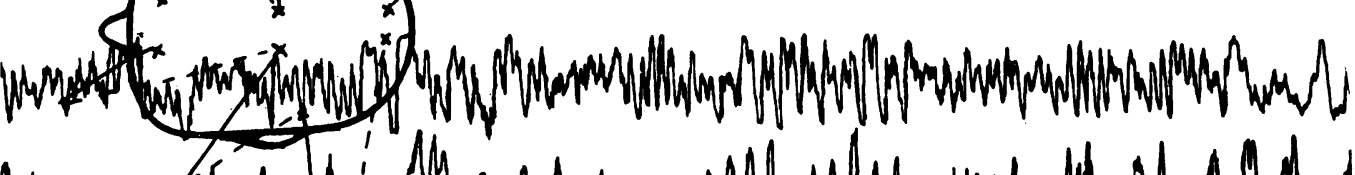

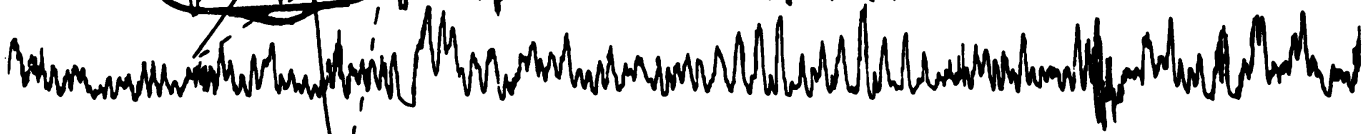

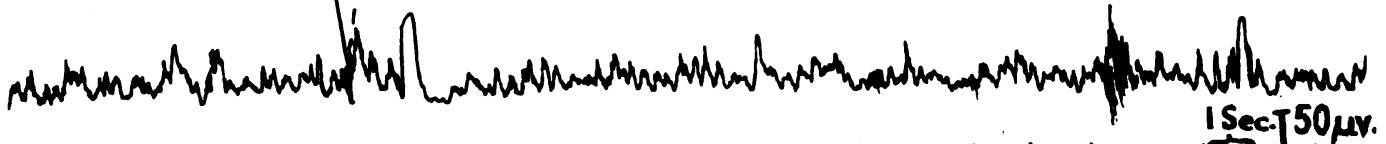

FIG. 6.-Case No. 6, aged $3 \frac{1}{2}$ years. Awake, on anticonvulsants. There is much generalized high-amplitude paroxysmal slow activity which has almost entirely disappeared by the age of 5 years and 7 months. 
C.R. 6 mths. Off anti-convulsants. (Awake)

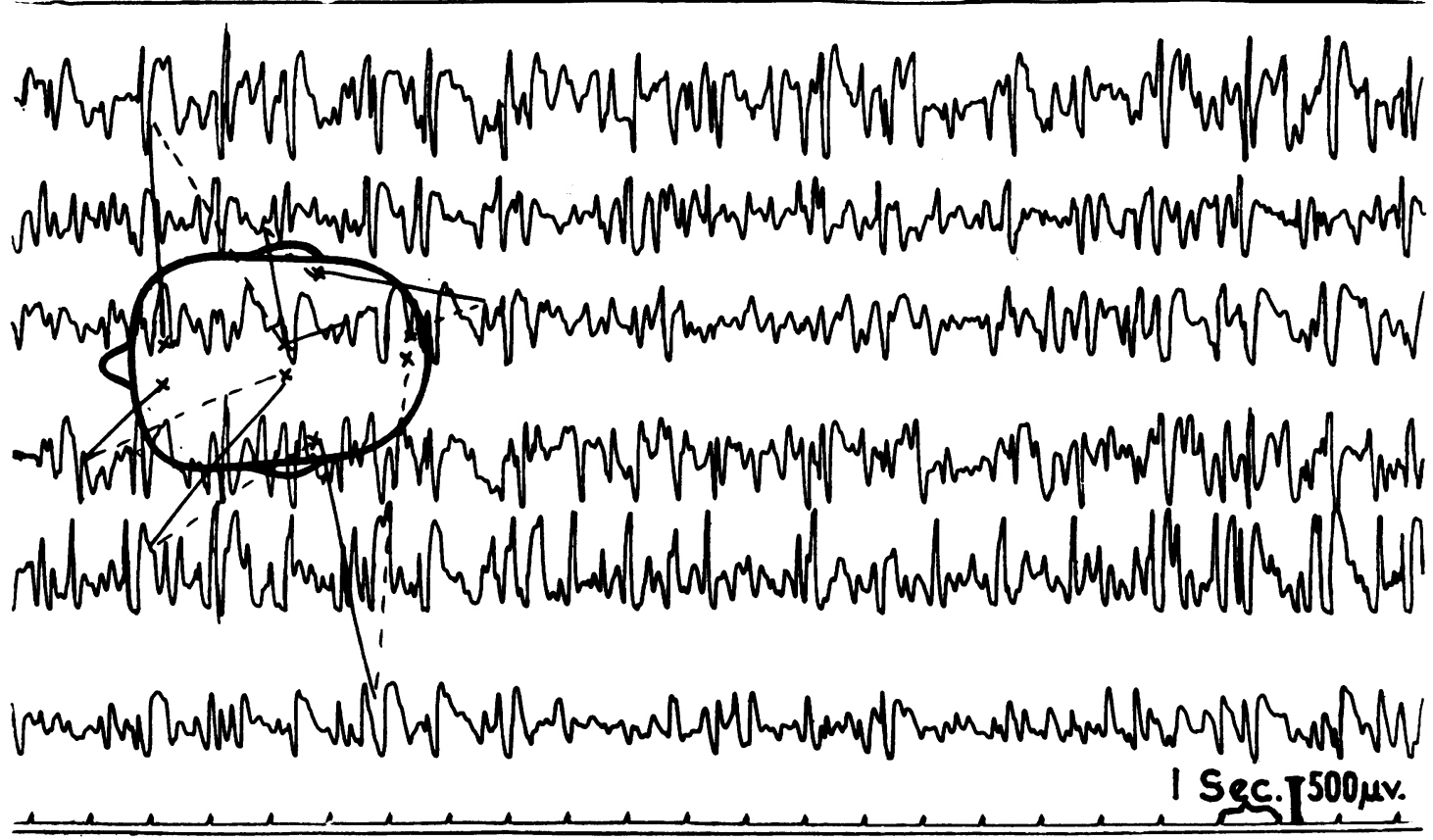

FIG. 7.-Case No. 9, aged 6 months. Waking record, off drugs. Extremely high voltage record with generalized spikey waves.

sequent examination at intervals confirmed the impression of severe mental deterioration. At the age of 3 years and 3 months she was a hyperkinetic destructive idiot. There had been no fits for six months.

Case 2. This boy began to smile at social overture at 6 weeks, and smiled at 3 months when his mother came into the room. He would hold objects for prolonged periods when they were placed into his hands at 4 months, and could reach out and grasp objects at $5 \frac{1}{2}$ months. He transferred objects from hand to hand at 6 months. He rolled from supine to prone at 4 months, could sit propped up for half an hour at $4 \frac{1}{2}$ months, and unsupported at 6 months.

At the age of 7 months he had a convulsion, lasting one or two minutes, consisting of dropping of the head, conjugate deviation of the eyes upwards, and of twitching of the left arm, followed by sleep. After that time, for the next three months, he had about seven attacks a day, in spite of treatment with phenobarbitone and phenytoin. He developed salaam spasms at the age of 8 months.

He stopped smiling within a day of the first convulsion, whereas previously he had been a happy baby. He used to laugh aloud repeatedly: with the onset of the fits the laughter stopped.

On examination (at the age of 9 months) there was a striking dissociation between the normal motor development and the absence of interest in his surroundings and in the test objects, and in the absence of smiling, laughing and play. Subsequent examination confirmed the diagnosis of mental deterioration.

Case 3. This boy began to smile in response to overtures at 6 weeks, and to vocalize when talked to at 8 weeks. At 3 months he would hold a rattle placed in the hand and play with it for some minutes. At 4 months he was said to be able to raise his head from the supine position. He would hold his feeding bottle, and would laugh aloud. In all respects he was developing normally.

At 4 months of age he was noticed to have a vacant look for a large part of the day, and a week later he had a fit, in which there was conjugate deviation of the eyes upwards; he was stiff and unconscious. He had about 20 fits a day for three days. There were no more fits for three weeks, but then they recurred. From the time of the first fit smiling and vocalizing ceased, and he appeared disinterested. He would take little notice of his mother when she lifted him up in her arms. He stopped taking interest in his food, and seemed lifeless. He did not appear to notice his toys, which previously he had enjoyed.

On examination at the age of 6 months, his motor development was normal. There was no spasticity. He could roll from supine to prone and head control was full. He could sit without support for a few seconds. The fontanelle and head circumference were normal. He showed so little interest in his toys that blindness was suspected. He would not follow the dangling ring. 
There was no smiling. Minor motor fits and salaams were observed.

Examination at subsequent dates confirmed the original impression that he had a degenerative condition, but vision was normal. He is now 5 years old, and is in a mental institution.

Case 4. This boy began to smile at 6 weeks and to laugh aloud at 3 months. He could raise his head from the supine position at 5 months, and drink from a cup at 6 months. He developed normally till 6 months. At $4 \frac{1}{2}$ months he became irritable, began to take less notice of his surroundings, and cried excessively even when picked up. At 6 months he began to have minor motor attacks, in which he became pale, stared for a second, had a sudden jerk, screamed and fell forward. He had about four a day. From that time onwards all smiling and laughing ceased.

When seen at the age of 7 months his motor development was that of a 5- to 6-month-old baby. He took little interest in his surroundings or in test objects. He would neither hold objects nor follow them with his eyes. Salaam spasms had occurred over the last month. The fits came under control, and from the age of 8 months to 3 years and 4 months he had no fits. He then had a minor motor convulsion, but there had been no further fits when he was last seen at the age of 4 years and 4 months. There had been no further deterioration, his I.Q. being assessed at 58 .

Case 5. This boy began to smile in response to overtures at 4 weeks, to sit without help at 6 months and to stand, holding on to furniture, at 8 months. In all other respects he developed normally till the age of 8 months, when he had a major convulsion, lasting for one minute, followed by a two hours' sleep. There was no associated fever. After the fit he was irritable, cried a great deal, but was eating normally. He seemed a different baby, just sitting in the pram and staring. He did not seem to take any notice of his surroundings, and all smiling and laughing stopped. He no longer reached out for objects. He had a further fit three days later and yet another four days after that. He was admitted four days after the first convulsion, and there were no abnormal physical signs other than those above. The cerebrospinal fluid and a radiograph of the skull were normal. The Wassermann reaction was negative. There was no phenylketonuria.

Salaam spasms developed at the age of 10 months, and fits occurred continuously for two years, in spite of treatment with phenobarbitone, phenytoin, 'primidone' and 'metharbital'.

His progress from the age of 8 months was that of a mentally defective child. He was seen at frequent intervals. He began to creep at 16 months and to walk at 24 months. By the age of 30 months he had not begun to say any words. His parents said that they could not teach him anything. He had difficulty in chewing solid foods and could not feed himself. There was no sphincter control. He was grinding his teeth.
He was a hyperkinetic idiot, and developmental tests were impossible.

Case 6. This girl began to smile at 5 weeks, and was following her mother's movements with her eyes at 8 weeks. She was able to grasp objects held in front of her at 5 months. She developed normally in all ways until 5 months, when she began to have minor motor fits. In these there was conjugate deviation of the eyes, the head was thrown back, the legs became stiff and she turned her feet in. The arms were then thrown out, and she gripped objects tightly. The attacks lasted for a few seconds only, and there were four or five a day. From the first day she was miserable, whimpered a lot and smiling ceased. The appetite remained unchanged.

She was seen three weeks after the onset, and in view of the change in the social behaviour a bad prognosis was given. There were no abnormal physical signs other than those above.

She was seen at repeated intervals. Salaam spasms began at the age of 9 months. The fits were uncontrolled by the usual treatment up to the age of 3 , when they ceased. She began to sit without help at 12 months, and to walk at 17 months. At the age of 5 years she was not saying any words. There was no sphincter control. She was a grossly retarded child with an unscorable I.Q. Fits had recurred.

An air encephalogram at the age of $3 \frac{1}{2}$ years was normal.

Case 7. This girl began to smile and to follow her mother with her eyes at the usual time. She could reach out and grasp her rattle at 5 months and between 4 and 5 months would play for hours with the straps of her pram. She was a happy, smiling, laughing baby until at the age of 6 months she had a convulsion. In the attack she appeared to choke, to shake from head to foot, the eyes turned up, she became stiff and the legs and arms twitched. The fit lasted for three or four minutes. Smiling ceased from the time of the first fit.

On examination at 18 months she was a severely retarded girl, with practically no interest in her surroundings. Her motor development was that of a 5-month-old baby. She had several fits a day until the age of 2 , but when last seen at the age of $4 \frac{1}{2}$, she had not had a fit for two and a half years. She could only say two words with meaning and was incontinent. Her I.Q. was too low to assess.

Case 8. This boy began to smile at 6 weeks. At 5 months he was able to reach out and grasp objects. He developed normally till the age of 6 months, when salaam spasms developed, and within a day or two all smiling ceased. He did not smile again for six months. He lost his ability to grasp objects but re-learnt the skill at the age of a year. He took no notice of anything for about six months, and just sat still in his pram, without moving the canvas covering. He had a major epileptic fit at the age of 2 years and 11 months. Salaam spasms occurred many times a day.

He was last seen at the age of 5 years and 10 months, 
when he was a hopeless ament and an I.Q. test was impossible.

Case 9. This girl developed normally, smiling, taking notice, playing and responding to sound, up to the age of 5 months, when she had a series of four major convulsions on one day and was admitted to hospital. From the day of the first fit onwards she stopped smiling. On admission she took so little interest in her surroundings that she was thought to be blind. A general convulsion was seen. An air encephalogram showed some distention of the ventricles. Apart from this and the electroencephalogram other investigations were negative. Her progress ceased, and when last seen at the age of a year she was an ament, with practically no head control.

Case 10. According to his mother, this boy had a difficult forceps delivery, and was shocked and ill after birth, with some twitching. He developed normally till $4 \frac{1}{2}$ months, having begun to smile, vocalize, look round and take notice at the usual time. At $4 \frac{1}{2}$ months he stopped smiling, became dull and staring for two weeks without apparent reason, and then developed major motor convulsions, seven or eight a day, each lasting one to two minutes. He would then lie for hours, doing nothing and not moving. All investigations were negative. At the age of 16 months he was a complete ament, with frequent salaam spasms and occasional major motor attacks. At the age of 3 years and 3 months his I.Q. was too low to assess.

Case 11. This boy was smiling at the usual time and following his mother with his eyes at 3 months. At 5 months he developed minor motor convulsions, with rolling of the eyes and sudden stiffening. Salaam spasms developed at 6 months. Immediately after the first fit he stopped taking notice of his surroundings, and showed no interest for a further 10 months. The fits were uncontrolled, occurring three or four times a day, and about 40 salaam spasms occurred every day.

He learnt to sit at 10 months and to walk at 18 months, but there was a striking lack of interest in his surroundings and lack of concentration. At the age of 4 years and 8 months he was an ament, with much toothgrinding, and unable to say any words, with an I.Q. which was too low to assess. Phenobarbitone, 'troxidone,' phenytoin and 'primidone' had failed to control his fits.

Case 12. This boy developed normally up to 4 months. He had begun to smile at 4 weeks. At 4 months he had a minor motor convulsion, becoming pale, looking vacant, with jerks of the head and several episodes of stiffening. He stopped watching people and showed much less interest in his surroundings, becoming listless. One to three fits occurred every day in spite of treatment. He began to sit at 9 months and to walk at 15 months, but he was unable to say as much as three single words till he was 2 years old. There was a striking dissociation between his motor and intellectual development. Progressive deterioration occurred, and at 2 years he was wrongly thought to be blind and deaf, on account of the lack of interest in his surroundings. He had numerous salaam spasms up to the age of 2 . When seen at the age of 5 years and 9 months he was an ament, with an I.Q. too low to assess. He had had only one fit in the last two and a half years.

\section{Discussion}

Though it is well known that repeated epileptic fits may be followed in time by mental deterioration, the clinical picture which I have described, namely, a period of normal development followed by the sudden and almost simultaneous onset of fits and mental deterioration, does not appear to have attracted attention. Friends in other centres have told me, however, that they not infrequently see this picture. Whether it occurs in older children is not certain. I saw a child at the age of $8 \frac{1}{2}$ years, one of 10 children, six of whom had died between the age of 8 months and a year with fits: she was said to have learnt to sit without support at 7 months and to walk without help at $\mathbf{1 0}$ months, and then to have developed fits and simultaneous mental deterioration at the age of 3 years; she was severely mentally defective when I saw her, with no other abnormal physical signs. Owing to the long interval, however, between the onset of the fits and the time I saw her and took the history, the story may have been inaccurate.

It is notable that in all the cases which $I$ have described the mental development was normal for the first few weeks. Livingston (1954) wrote: 'We have studied a group of 570 patients in whom mental retardation and recurrent convulsive seizures appeared during the first year of life. Evidence of mental retardation was present in all of them prior to the onset of convulsions.' This series included, presumably, children with abnormal neurological signs, such as those of cerebral palsy. I have seen a child who had evidence of backwardness before fits occurred, but who then deteriorated immediately and severely. There was no family history of fits or of mental defect. He began to smile at the age of 3 months, and to vocalize and take interest in his surroundings about a month later. At the age of 4 months he developed convulsions and forthwith stopped smiling and showing interest in his environment. When seen by me at the age of 9 months he was an ament with frequent fits and grossly defective motor development, his head control being little better than that of a 6-week-old baby. This boy differs from the series of 12 cases described above, not only in the evidence of previous backwardness, but in the gross defect of motor development. In the other patients who were seen shortly after the onset, the striking feature was the normal motor 
development, confirming the mother's history of previous normal progress, with grossly abnormal social behaviour.

The nature of the pathological lesion in these cases is a matter of conjecture, and it is unfortunate, as already stated, that more air studies were not performed, but at the time they did not seem to be justified. The absence of an abnormal birth history, and the fact that all the babies were full term, is striking. There are many who feel that a normal delivery, with the absence of any signs of birth injury in the immediate post-natal period, by no means excludes the possibility of such injury (Penfield and Jasper, 1954). At the Jessop Hospital for Women at Sheffield, we follow up all babies with an abnormal birth history, including all those who suffered from asphyxia, neonatal convulsions, cerebral irritability and cerebral haemorrhage, but in eight years I have never seen one develop the picture which I have described. Nevertheless, it is possible that birth injury is the cause of the syndrome, though it is difficult to understand the mechanism involved.

The clinical picture of the cases described does not in the least suggest that the fits are the cause of the mental deterioration. In this connexion the mental changes in four of the children before the fits began are of particular importance. The immediate or almost immediate onset of mental changes in the remaining children, following in six cases a minor motor seizure lasting for a few seconds only, makes such a cause of the deterioration unlikely. It is well known that the much more severe febrile convulsions do not lead to any mental deterioration. It is far more likely that some change occurs in the brain which causes both the fits and the deterioration. The absence of any preceding infection, especially diarrhoea, and the absence of any abnormal neurological signs, make thrombosis or haemorrhage improbable.

The high incidence of salaam spasms or akinetic seizures in these cases is of interest. It may well be that, as Bridge (1949) suggested, they are due to a deep and diffuse brain lesion, and that this explains the view that they are usually associated with severe mental deterioration, and that they are difficult to control.

The E.E.G. picture in our patients was identical with that described by Gibbs and Gibbs (1952) under the title 'Hypsarthymia' in a series of 132 infants with similar motor convulsions. In two-thirds of their patients there was no known aetiology, but they regarded the changes in the E.E.G. as indicating a diffuse lesion of the brain, possibly due to a bacterial or virus disease in the mother during gestation.
They did not mention, however, the developmental history of the infants before the seizures began.

In assessing the prognosis in an individual infant who develops fits without abnormal neurological signs or known cause, such as fever, it must be remembered that in the vast majority of cases, provided that the fits are brought under control, no mental deterioration will ensue. The various studies which have been made of the subsequent intelligence of children who had convulsions in infancy are of little value in assessing an individual. One difficulty is that these studies bunch together convulsions of different aetiology, instead of separating them off into the various types and causes. In my opinion the prognosis can only be assessed by a thorough developmental examination, with special emphasis on the child's social behaviour, his responsiveness, alertness, and interest in his environment. If these are abnormal, the prognosis should be very guarded, until repeated observation permits a more definite statement. It must be borne in mind that excessive irritability, the loss of smiling, and a reduction in the interest in surroundings may be due to many causes, and a thorough physical examination is necessary in all cases.

\section{Summary}

Occasionally an infant develops normally for a few months and then suddenly develops fits and mental deterioration without apparent cause and without abnormal neurological signs other than those of retardation.

Twelve cases of this type are described. In four of them certain changes occurred in the child's behaviour shortly before the fits developed: in the others there was a change in the child's behaviour, notably the stopping of smiling and of interest in his surroundings, immediately after the first fit. On examination shortly after the onset there was a striking dissociation between the child's normal motor development and the defective social responses. Severe mental deficiency followed. It was thought that these cases must be due to an underlying brain lesion.

My thanks are due to Dr. J. W. Warboys for the electroencephalograms and for reporting on them, to Dr. T. Lodge for the $x$-ray studies and to the Photographic Department of the United Sheffield Hospitals for the reproductions. I also wish to thank the family doctors who referred the children to me. One of the patients is under the care of Dr. T. Colver, to whom I express my thanks for permission to record the details of this boy and for allowing me to examine him.

Bridge, E. M. (1949). Epilepsy and Convulsive Disorders in Children. New York.

Gibbs, F. A. and Gibbs, E. L. (1952). Atlas of Electroencephalography, vol. 2, ch. 6 . Cambridge, Massachusetts.

Livingston, S. (1954). The Diagnosis and Treatment of Convulsive Disorders in Children. Springfield, Illinois.

Penfield, W. and Jasper, H. (1954). Epilepsy and the Functional Anatomy of the Human Brain. Boston. 